\title{
GEOGRAFIA E A EXPERIÊNCIA DO MUNDO'
}

\author{
Amélia Regina Batista NOGUEIRA²
}

\section{Resumo}

Geografia e a experiência do mundo é um breve ensaio para continuar o dialogo com aqueles que pensam construir uma ciência geográfica em que o universo do conhecimento vivido, produzido pelos homens e mulheres que experienciam os lugares e as paisagens, possam ser valorizados e reconhecidos como conhecimento que mostra o mundo tal qual ele é. Nossas descrições, reflexões e representações nada perdem ao deixar fluir uma narrativa sobre os lugares e as paisagens por quem a experiência, assim como nossos mapas, poderia repensar sua escala, partir da escala que representa a vida cotidiana, pois nela tem histórias, tem elementos simbólicos, paisagens visíveis e invisíveis. É a partir dessas proposições que o texto se propõe a dialogar.

Palavras-chave: Experiência; Lugar; Paisagem; Mundo vivido.

\section{GEOGRAPHY AND THE EXPERIENCE OF THE WORLD}

\begin{abstract}
Geography and the experience of the world is a brief essay to continue the dialogue with those who think the universe of lived knowledge, produced by men and women who experience places and landscapes, can be valued and recognized as knowledge that shows the world how it is. Our descriptions, reflections and representations lose nothing by letting a narrative flow about places and scenarios by those who experience it, like our maps, we could rethink their scale, starting from the scale that represents everyday life, because it has stories, it has symbolic elements, visible and invisible views. It is from these prepositions that the text proposes to dialogue.
\end{abstract}

Keyword: Experience, place, lanscape, lived world

\section{GEOGRAFÍA Y LA EXPERIÊNCIA DEL MUNDO}

\section{Resumen}

Geografia y la experiência del mundo es un breve ensayo para continuar el dialogo con aquellos que piensan construir una ciência geográfica en la cual el universo del conocimiento vivido, producido por los hombres y mujeres que viven en experiências en los lugares y en los paisajes, puedan ser valorados y reconocidos como conocimiento que muestra el mundo tal cual es. Nuestras

\footnotetext{
${ }^{1}$ Texto apresentado em palestra realizada no II Congresso Brasileiro de Organização do Espaço (II CBOE) e XIV Seminário do Programa de Pós-Graduação, realizado na cidade de Rio Claro/SP, entre os dias 24 a 28 de março de 2019, intitulado "Soberania e Ciência no século XXI: a decolonialidade do saber como novo paradigma geográfico?".

2 Professora Associada da Universidade Federal do Amazonas - UFAM. Doutora em Geografia Física pela Universidade de São Paulo - USP. E-mail: ameliabatista@ufam.edu.br
} 
descripciones, reflexiones y representaciones nada pierden al dejar fluir una narrativa sobre los lugares y los paisajes por quien la vive en experiencia, asi como nuestros mapas, podrian repensar su escala, partir de la escala que representa la vida cotidiana, pues en ella tiene historias, tiene elementos simbólicos, paisajes visibles e invisibles. Es con base en estas proposiciones que el texto se propone dialogar.

Palabras clave: Experiencia, lugar, paisaje, mundo vivido

\section{INTRODUÇÃO}

Um texto direcionado a compreender a ciência geográfica, costuma iniciar trazendo citações de pensadores e pesquisadores que se preocupam com o desenvolvimento científico, portanto, buscam de forma racional e lógica, analisar objetivamente um fenômeno que ocorre no espaço, cabe ao estudioso, demostrar e provar a veracidade dos fatos, ou no mínimo apontar algumas considerações finais. Esse ensaio, não vai fugir tanto dessas exigências acadêmicas, nossos argumentos dialogarão com pensadores da geografia, da filosofia, da psicologia e da literatura que buscam entender o mundo a partir daqueles que experienciam e vivenciam os problemas. Porém, quero iniciar, citando o famoso escritor francês, Saint-Exupéry e sua mais conhecida obra, "O pequeno Príncipe”.

O capítulo XV dessa obra tem como título: “O geógrafo”. Nas andanças pelo mundo, o "pequeno príncipe" (que era de outro planeta) encontrou um geógrafo, que por sua vez, o confundiu com um explorador. Travam um diálogo, em que um tenta compreende o mundo do outro, o pequeno príncipe fica entusiasmado quando ouve do geógrafo, o que ele faz, segundo o geógrafo, ele é "um especialista que sabe onde se encontram os mares, os rios, as cidades, as montanhas e os desertos”, o principezinho a medida que ouvia o geógrafo, se encantava e também se decepcionava, travou-se uma discussão acadêmica, o geógrafo ao mesmo tempo que argumentava conhecer a Terra, não era um explorador, não ia ao mundo, pois essa era função do explorador, a ele caberia verificar se os fatos e as coisas que o explorador dizia e trazia (pedras) eram verdadeiras.

Mas, como ser um especialista que sabe onde se encontram os mares, os rios, as montanhas e as cidades, mas nunca ter ido a elas, nunca ter ido ao 
mundo? O principezinho então quis saber do geógrafo o que tinha no planeta terra, já que esse era o lugar onde ele habitava, qual foi a decepção do principezinho, quando perguntou se no planeta Terra havia montanhas, mares, cidades, desertos, rios? E ouvir o geógrafo dizer que não sabia, que o geógrafo é muito importante para estar passeando, sair de sua escrivaninha, isso quem fazia, insistia o geógrafo, era o explorador, o geógrafo ouvia seus relatos, anotava, buscava comprovar a veracidade dos fatos, a começar por verificar a moral do explorador e anotava no seu livro.

Agora era o geógrafo quem interrogava o principezinho, acreditando que este, por estar viajando pelo mundo, era um explorador. O geógrafo com essa certeza interrogou o príncipe sobre seu planeta, pois estava pronto para registrar no seu livro tudo o que fosse relatado, por sua vez o príncipe respondeu que no planeta dele só havia três vulcões e uma flor, o geógrafo ressaltou que a flor ele não iria registrar, o principezinho ficou desolado, não se conformando com a revelação do geógrafo, quis saber "por quê? porque as flores são efêmeras". Não entendendo o que significava efêmera, o principezinho partiu desolado. Ele amava aquela flor. Ela tinha um significado simbólico e afetivo e de existência. Precisava ser descrita.

O diálogo do principezinho com o geógrafo, nos põe em discussão as perspectivas teórico metodológica da ciência, e da Geografia em particular. Os fenômenos são descritos muitas vezes de forma distanciada, o mundo da existência e seus significados, quase sempre são entendidos como dados das subjetividades, e a ciência é objetiva, além de que a ciência prima por verdades mais eternas, daí uma flor não interessar para o geógrafo.

Como a flor não iria estar na descrição do planeta do pequeno príncipe, se ela era o que tinha de mais importante, no seu planeta? E aqui lembramos Husserl, que nos chama atenção de que "é preciso que o pensamento filosófico retorne as suas origens dando-se como ponto de partida, não mais as opiniões dos filósofos, mas a própria realidade. (Husserl,1955, p.77), seja essa visível ou invisível. O diálogo dos personagens imaginados por Exupéry, nos leva a pensar nos caminhos percorridos pela ciência geográfica, e esses muitas vezes se distanciaram do mundo vivido, do mundo da experienciação, do mundo tal qual ele se apresenta. 
Para haver essa aproximação, propomos uma subversão metodológica, assim uma "Geografia subversiva", ou uma outra Geografia Radical. Parto de uma Geografia como uma ciência que busca compreender o mundo. Esse mundo entendido como lugar dos homens e mulheres. Lugar não apenas como localização, mas como fenômeno experienciado por homens e mulheres que nele vivem. Aquele homem e aquela mulher para quem "a realidade geográfica é primeiramente o lugar em que está, os lugares de sua infância, o ambiente que lhe chama a sua presença”. (Dardel, 2011, p.10).

O pesquisador não se distancia para ver, ele se aproxima, se inseri, se encarna. Percebemos aqui, que se trata de uma outra proposta radical de pressuposto filosófico de ciência, assim uma outra Geografia Radical. Partimos então dos geógrafos e geógrafas que procuram fazer uma leitura do mundo através de uma interpretação fenomenológica: inicialmente Erick Dardel, Edward Relph, Yi Fu Tuan, Anne Butimer. No Brasil, Werther Wolzer, Eduardo Marandola, Lívia de Oliveira, Lucia Helena Gratão, João Batista de Melo.

Procuramos compreender os homens e mulheres, enquanto sujeitos que estão no mundo, que tem dele uma experiência própria, uma experiência de vida, de existência, como Merleau-Ponty, entendemos que enquanto ser no mundo:

\begin{abstract}
"não estou no espaço e no tempo, não penso o espaço e o tempo, eu sou no espaço e no tempo, meu corpo aplica-se a eles e os abarca. A amplitude dessa apreensão mede a amplitude de minha existência; mas de qualquer maneira ela nunca pode ser total, o espaço e o tempo que habito de todos os lados tem horizonte indeterminados que encerram outros pontos de vista" (PONTY-MERLEAU, 1996, p.249).
\end{abstract}

Desta forma compreendemos que ao estar e ser no mundo, faço dele o meu lugar, sendo esses não a totalidade do mundo, mais aquela parte que para mim é singular, no qual faço minha história, dando significado para cada coisa que aí está, e que tenho uma relação de existência, como a relação do pequeno príncipe com a flor, que mesmo efêmera marca uma história com o lugar e suas paisagens, daí podermos pensar uma Geografia que olha o mundo, e aqui já podemos pensar o mundo enquanto a Terra, e essa, por sua vez, ser pensada a 
partir dos diferentes olhares, dos diversos sujeitos que habitam os mais variados lugares e caminham, compreendendo suas diferenças, assim, produzem nela diversas formas de paisagens ao longo do tempo.

Assim sendo, como entendeu Dardel (2011), há uma geograficidade construída na relação intersubjetiva entre os homens, mulheres e a Terra,

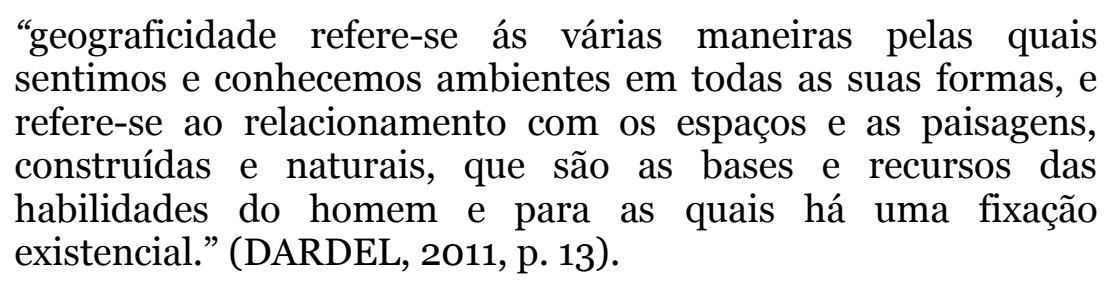

À vista disto, podemos entender que ser é estar. A partir desses caminhos pretendemos fazer uma Geografia que comece pelas experiências pré-científicas, pelas experiências de quem vive, percebe e constrói os lugares. Assim como entendermos as intersubjetividades entre os homens, mulheres e a Terra, retomar o princípio da descrição, da grafia da Terra, descrever os lugares vividos a partir daqueles que os vivenciam, despertando a experiência que cada um tem com a Terra e seus lugares e paisagens, lembrando que a Geografia é o saber e o conhecimento científico que ao longo da história da Terra a descreve e a representa, desvelando inúmeros lugares e paisagens.

\section{A TERRA COMO PAISAGEM E LUGAR-ESPAÇO VIVIDO}

Costumamos pensar as categorias lugar e paisagem em textos separados, aqui gostaria de partir do entendimento de que no mundo real, nossa percepção e olhar ao se voltar para o lugar, o reconhece pelas suas paisagens, didaticamente talvez seja mais claro discutirmos essas categorias de forma separada, mas estou nos colocando um desafio: já compreender que os lugares tem uma forma, um conteúdo, uma função e um significado simbólico e afetivo, além de que todas essas dimensões são processuais, ou seja, tem também um caráter de tempo. Essas dimensões vem a nós como paisagem, que por sua vez, também estão carregadas de forma, função, conteúdo, signos, símbolos e afetividades, se intercruzam demostrando a dimensão da existência humana. 
Nossa dimensão humana nos faz perceber o mundo com nosso corpo. Com ele sentimos as coisas que estão no mundo: os objetos, a natureza, os homens e mulheres dos lugares e suas paisagens. São esses os responsáveis pela construção de seu mundo vivido. O lugar-espaço vivido é a espacialidade que revela a experiência do espaço, aquela dada na relação do meu corpo com o mundo e com os outros a partir de uma relação intersubjetiva.

O lugar é produzido no dia a dia na relação de trabalho, de afetividade, de rejeição, de circulação, de produção de ideias. A Geografia que parte do mundo da experiência, ver e ler o lugar-espaço vivido para além da localização, da geometrização do espaço, como já nos chamava atenção Dardel (2011) "o espaço puro do geógrafo não é o espaço abstrato do geómetra: é o azul do céu, fronteira entre o visível e o invisível. O espaço concreto da Geografia liberta-nos do espaço humano infinito da geometria ou da astronomia" (Dardel, 2011, p.8 ). O autor nos fez crer que devemos fazer uma geografia que parta do mundo da experiência vivida, pois essas nos revelam também o que é o lugar, quais seus significados e símbolos, como elas ficam materializadas nas paisagens, que é a grafia que nos mostra a presença humana no mundo.

O lugar como extensão da existência humana, é construído a partir de uma relação de afetividade, de identidade (Tuan,2012 Buttimer, 1976). O lugar tem alma, cheiro, barulho, sabor, estética. O lugar é percebido com o corpo, com todos os sentidos. O lugar possui espírito, personalidade. Cada lugar é único, singular. Desta forma para cada lugar há uma paisagem. A verdade da paisagem emerge não como teoria geográfica, mas como expressão fiel da existência. (DARDEL, 2011). As paisagens são as marcas dos lugares, elas dizem o que o lugar é, expressa ainda a memória do que o lugar foi (palácios, murros, castelos, parques, igrejas).

Percebemos e conhecemos os lugares através de suas paisagens, essas são entendidas como marca da existência humana, percebemos a partir delas, que o lugar pode ser de moradia, de trabalho, de amizade, de lazer, de mistérios, de múltiplas territorialidades, de diversidades culturais, religiosas, as paisagens expressão as relações de gênero (a casa como lugar da mulher). Os lugares migram com seus habitantes, assim como migram com eles as paisagens, mesmo que de forma simbólica: plantar aquela roseira que tinha lá no meu 
lugar, construir minha casa da mesma forma que tradicionalmente fazia lá, são atos de reconstruir os lugares e suas paisagens de existência, construo assim, uma paisagem deslocada do lugar, mas que o representa, que simbolicamente o reflete.

A paisagem é marca, expressa uma civilização. É vista por um olhar, apreendida por uma consciência, valorizada por uma experiência, julgada por uma estética e uma moral, essa política. Cada cultura imprime na paisagem a marca que lhe é própria. A marca imprimi um sentido, que implica toda uma cadeia de processos físicos, mentais e sociais, assim a paisagem é matriz, é a expressão da existência do homem no mundo ao longo da História.(...) A marca da existência Humana não pode ser pensada sem compreender a natureza física da Terra, é na correlação intersubjetiva entre o homem e a Terra que produzimos paisagens: Essas, tem múltiplos signos, significados e símbolos dado por quem experiência os diversos lugares e marcam neles suas histórias: de tragédias, de guerras, de ódio, de amor, de harmonia, de lutas políticas, de religiosidades, de festas..(BERQUE, p. 239).

Desta forma, como nos chama atenção Cosgrove (2012), vemos que a geografia está em toda parte, pois o ato de geograficizar a terra, é um ato humano, que se dá numa relação de existência, de geograficidades. A paisagem é um revelar do lugar, daí ser recheada de signos, símbolos e significados. Nosso comportamento se diferencia diante das paisagens, ao adentrarmos em uma igreja, caminhamos silenciosamente, seja como ato de devoção, seja de contemplação, pois esses templos por si só falam a história e a vida do lugar: como esses são conduzidos pela religiosidade, como essa religiosidade se impôs, como ela é traduzida por quem vive o lugar, em outro momento, quando estou no parque me revelo de outra forma, grito, corro ao mesmo tempo que obedeço o regulamento de "não pisar na grama", "não dar comida aos animais", "não usar trajes de banho", assim percebo a dimensão política e simbólica da paisagem e dos lugares. Segundo Cosgrove (2012),

"todas as paisagens são símbolos. Muitos não são aparentes, mas servem como normas e reprodução de grupos: parques e as condutas de uso, de comportamento e de ordem, símbolo da moral (bar não é lugar para mulheres). Possuem significados simbólicos porque são produtos da apropriação e transformação do meio pelo homem. (COSCROVE, 2012, p. 227). 
Refletindo a partir do meu lugar, o Amazonas, e de suas inúmeras comunidades ribeirinhas espalhadas pelas várzeas do rio Amazonas-Solimões, algumas delas foram meus espaços de pesquisa e de minha forma de inserção no mundo, reconheço que meus primeiros contatos com essas paisagens no primeiro momento foram de encantamento, de uma chegada cautelosa, pois havia mais paisagens invisíveis dando significado ao lugar, do que aquelas que no primeiro contato me encantavam com sua beleza estética, com sua dimensão oceânica, com os cheiros do mato e de seus múltiplos sabores, mas, que também me causavam medo.

Aos poucos fui compreendendo que além de tudo isso, que meus sentidos poderiam perceber, os lugares se organizavam, se territorializavam, a partir de alguns seres quase invisíveis para mim; as cobras grandes, que estão sempre presentes nos grandes lagos, que todos afirmam existir, mas, poucos conseguiram ver, outros já encontraram, porém, afirmavam que ainda não eram as maiores.

Esses seres, também são responsáveis pela forma de uso e circulação nos lugares, eles estão presentes na organização da vida de pescadores, que se afastam dos lagos onde ela pode estar, o afastamento da casa da beira do rio, quando se percebe que a "cobra grande", começou a cavar na beira do rio e a terra "vai cair". Esses e outros inúmeros seres da floresta, dão significados as paisagens e aos lugares. É preciso que a Geografia revele, descreva e compreenda os lugares e suas paisagens em suas múltiplas dimensões, e aqui percebemos a importância da dimensão cultural e simbólica.

É preciso reaprender a ver o lugar e suas paisagens, esta reaprendizagem se dá a partir das histórias narradas por quem vive os lugares. São os sujeitos que dão significados ao lugar e as paisagens. Assim é preciso repensar a Geografia, trazer a dimensão da experiência daqueles que de fato experienciam os lugares e suas paisagens, é necessário nos perguntarmos sobre algumas verdades absolutas que construímos a partir de uma visão de mundo, de uma visão de ciência e que acabou nos afastando dos saberes sobre os lugares onde a vida acontece, mesmo sem o conhecimento científico: quem disse que Greenwich é o meridiano principal, sustentamos essa informação mesmo sabendo que foi um acordo internacional (1884), que outros meridianos 
principais se encontram registrado na história da geografia da terra: Meridiano de Paris (França), de Cádis (Espanha) e de Coimbra (Portugal).

E importante compreendermos que a ciência tem também um caráter político, nossos dados foram produzidos diante de teorias ocidentais, nada perdemos ao considerar as verdades ditas por aqueles que têm uma experiência vivida com o lugar, é compreender como Merleau-Ponty, que o:

\begin{abstract}
"pensamento não é nada de "interior", ele não existe fora do mundo e fora das palavras (...) posso sobrevoar um "lugar" em pensamento, imaginá-lo ou desenhar sua planta no papel, mas mesmo então eu não poderia apreender a unidade do objeto sem a mediação da experiência corporal, pois aquilo que chamo de uma planta é apenas uma perspectiva mais ampla, é o lugar visto de cima, e, se posso resumir nela todas as perspectivas costumeiras, é sob a condição de saber que um mesmo sujeito encarnado pode ver alternadamente de diferentes posições" (MERLEAU-PONTY, 1996. p. 249).
\end{abstract}

Ver em diferentes posições é ver mais de perto e assim ter mais possibilidade de se aproximar das verdades sobre os lugares e suas paisagens. Partir daqui, é fazer uma geografia por baixo, não inferior, mas reconhecendo que o conhecimento científico e o "primeiro ato filosófico da busca do conhecimento seria retornar ao mundo vivido aquém do mundo objetivo" (MERLEAU-PONTY, 1996, p. 84). Desvelar os lugares e as paisagens tomando como princípio a percepção sobre os lugares a partir de quem os vive.

Não apenas levantar dados e informações, mas considerar as verdades narradas sobre os lugares a partir de quem o experiência; Refazer a Geografia brasileira, fazer uma Geografia a partir das narrativas das etnias que ainda defendem seus territórios, como no Amazonas os Tucanos, Dessanas, Ticunas, Waimiri Atroari, Macuxi também os Guarani, Kaingang, Xetá, Xocleng (Sul) ,Terena, Xavante, Potiguara, além dos inúmeros quilombolas rurais e urbanos, camponeses, e ainda das centenas de "tribos urbanas", que se territorializam nos grandes centros urbanos.

A Geografia deve procurar ainda uma outra forma de representar que não seja apenas a partir de uma cartografia oficial, pautada em convenções e geometricamente calculada, em que os mapas, são representações alheia a realidade vivida. A geografia deve se aproximar de uma outra cartografia, a que 
reconhece os mapas mentais que cada sujeito conhece e que o faz circular nos lugares.

\section{A GEOGRAFIA É A CIÊNCIA QUE REPRESENTA O MUNDO}

A geografia feita por baixo deve mapear os lugares considerando os Mapas Mentais como a representação primeira sobre os lugares. Nos mapas mentais são representadas as coisas que identificam o lugar, neles podem estar representado o visível e o invisível a paisagem material e simbólica. Os Mapas Mentais são representações dos nossos lugares de existência. Traçados através de um processo no qual relacionam-se percepções próprias (visuais, olfativas, auditivas), as lembranças, as coisas conscientes e inconscientes, o pertencer a um grupo social, cultural. Todo sinal contido nos mapas tem uma leitura simbólica dos lugares e suas paisagens.

Os mapas mentais representam a relação que cada um tem com seu lugar de existência, pois o que fica representado no mapa, como por exemplo um rio, ao estar representado aí, demonstra também uma relação simbólica que se tem com ele, não é visto apenas como resultado da dinâmica da natureza, ou uma expressão socioeconômica em que o rio, é para muitos pescadores e comandantes de embarcações, lugar de trabalho. Os mapas mentais além dessas variáveis, devem representar as coisas que possuem um significado simbólico para aquele que cartografa. Um mapa mental é a grafia dos lugares e paisagens vividas. Daí serem tão importantes quanto os mapas geometricamente representados. 
Mapa 1: Mapa Mental de adolescente ribeirinho da comunidade Nossa Senhora do Perpétuo Socorro. Município de Tefé.

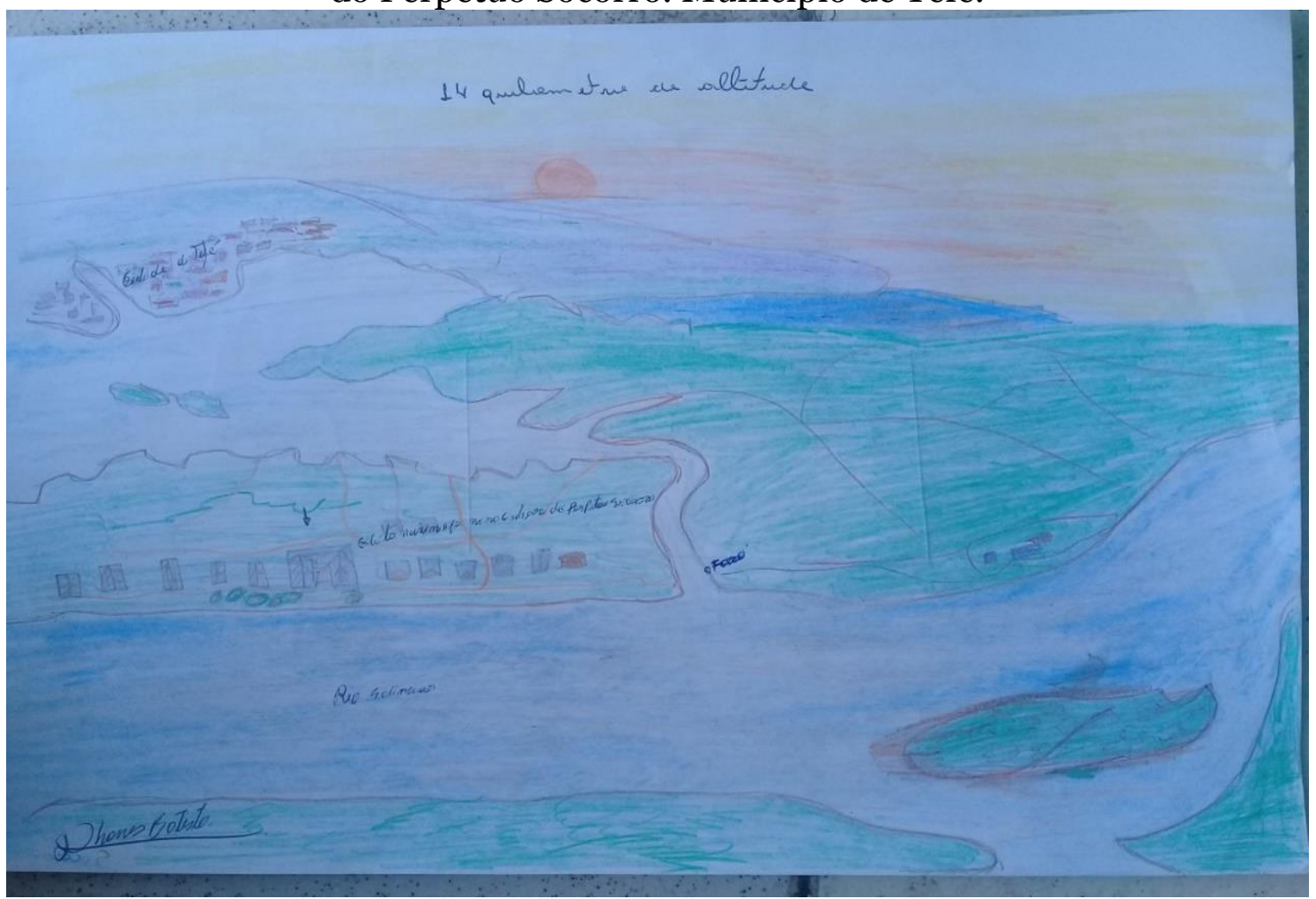

Fonte: Dissertação de Mestrado de Rondinelly Pereira de Souza. PPGEOG-UFAM. 2017.

A intensão dessa pesquisa foi compreender a percepção dos jovens do lugar e das paisagens daí. Esses adolescentes colocam a cidade ao fundo em segundo plano, o primeiro plano é a comunidade, seu lugar de existência. Ao falar sobre ela, o adolescente deixou claro que há uma dimensão topofílica entre ele e o lugar. A cidade está longe, ela não interessa nesse momento, seu mapa mental possui uma marca da afetividade, da relação de geograficidade, cada coisa que aí está representada, tem um significado.

Os mapas mentais abaixo, foram desenhados por professores da etnia Tucano em São Gabriel da Cachoeira, a 852,56 quilômetros de distância de Manaus, o objetivo era de localizar as escolas públicas que tem ao longo das aldeias. Chama-nos atenção, a precisão e detalhes da rede hidrográfica, nenhum rio ou igarapé (rio pequeno), deixou de ser representado. Todos eles são navegáveis, porém no período da vazante (julho/dezembro), quando os rios estão baixos, apenas canoas tem acesso. Segundo relatos, existem pequenos trechos que ficam tão "seco", que é preciso caminhar e aí é a canoa que é levada nas costas, "é preciso conhecer bem esses rios, se tu não conhece, tu te perdes, 
fica mal, porque nem peixe tem nesse lugar quando tá tudo seco, tem que conhecer", nos relatou um professor Tucano. Um detalhe que eles não esquecem e de registrar no mapa quantos litros de gasolina o motor consome no percurso, pois se acaba, não tem como abastecer, "quem não sabe, vai ter problema”.(Mapa Mental 2, 3). Esse conhecimento é de vida, de existência, uma geografia do mundo da experiência.

Mapa 2: Mapa mental de professor indígena em São Gabriel da Cachoeira, aqui está representado a comunidade indígena São Joaquim. Distante da cidade de São Gabriel. Segundo o professor, três dias de canoa com motor 4ohp. E da casa dele 3 horas de canoa até a escola. São Gabriel da Cachoeira- AM. 2017.

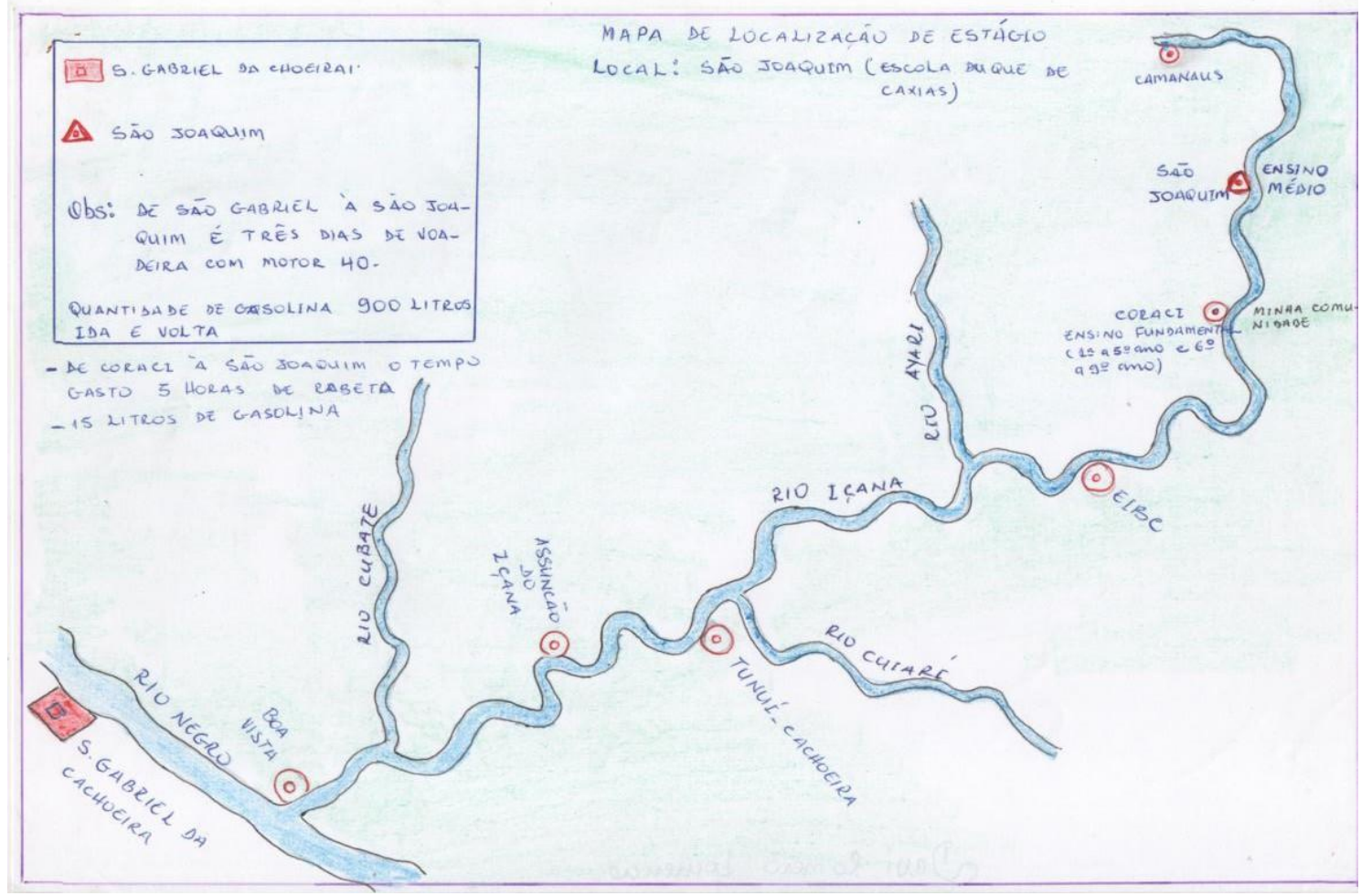

Fonte: Estágio supervisionado do curso de Licenciatura Plena em Geografia. UFAM. Amélia R. B. Nogueira, 2017. 
Mapa 3: Mapa Mental de professor indígena. Rios, comunidades, pequena pista de pouso, representado pelo avião. Em cada ponto vermelho menor, há uma pequena escola. São Gabriel da Cachoeira-AM.

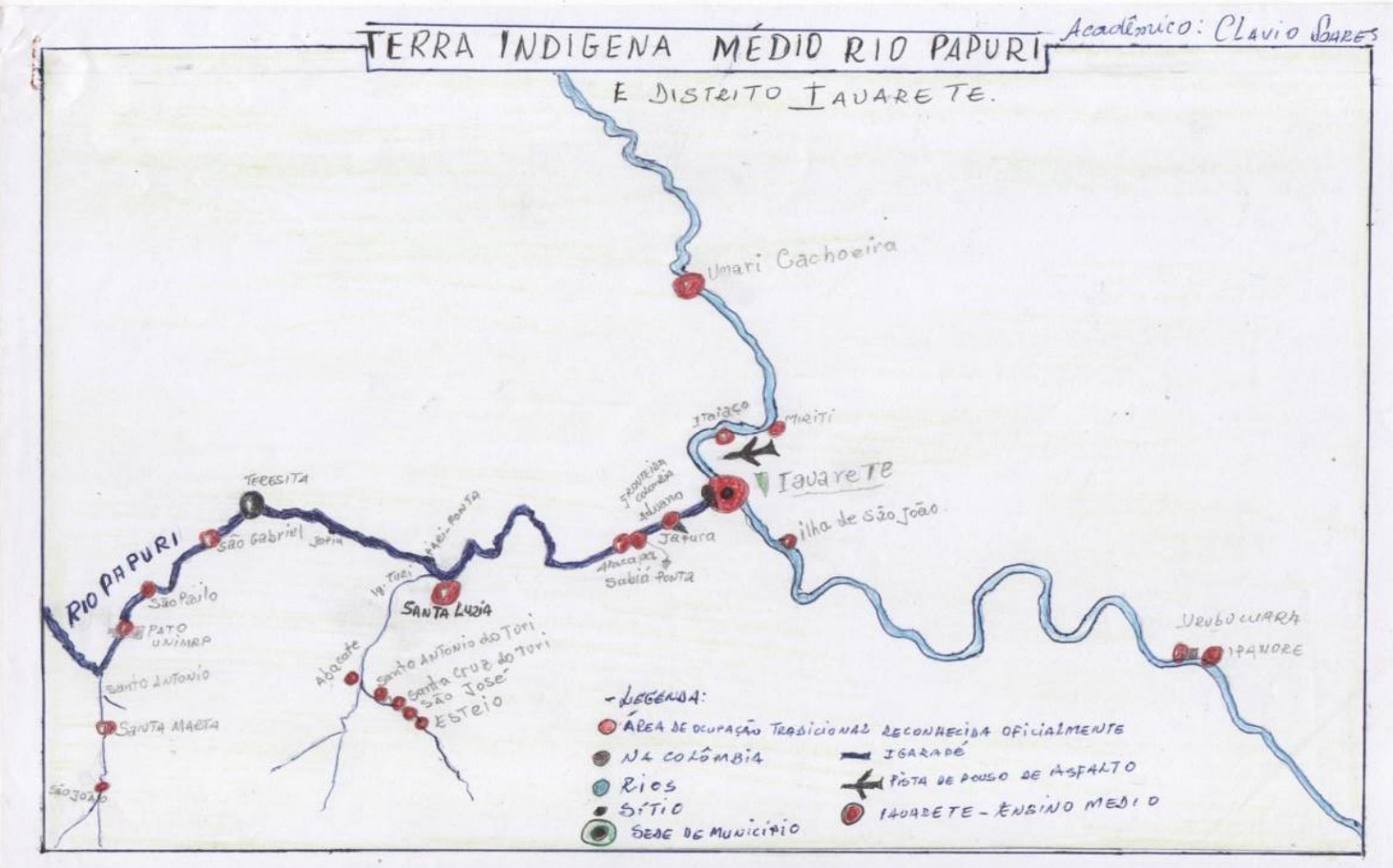

Fonte: Estágio supervisionada do Curso de Licenciatura Plena em Geografia. UFAM. Amélia R. B. Nogueira, 2017.

\section{ÚLTIMAS PALAVRAS...}

Retomando a conversa inicial, pensar uma geografia da experiência do mundo, uma geografia em que parta do mundo vivido, do mundo das experiências existências, é reabrir um diálogo na ciência com todos e todas que vivenciam o mundo, das crianças aos adultos de qualquer lugar da terra e das mais diversas culturas.

A ciência se distanciou dos saberes, procurou sozinha fazer uma análise dos fenômenos observados, particularmente, a Geografia, cuidou de dizer, como bem descreveu o geógrafo do pequeno príncipe, onde estavam as montanhas, os rios, as florestas, as cidades, em outro momento quantas montanhas tinham, quantos rios, quantas cidades, quantas pessoas. Não perguntou como viviam as pessoas nas montanhas, nas margens dos rios e mares, nas florestas, nas cidades? O que significa viver nesses lugares? O que significa cada lugar, cada paisagem construída, como foram construídas e reconstruídas? Quem 
construiu? Como construiu? Com que interesse construiu? Muitas perguntas precisamos refazer e buscar as respostas também com aqueles que conhecem os lugares, porque os vivem e lutam por eles, repensar nossas escalas de análise, nosso mapas geometricamente pensado, de localização precisa, transformam em pontos o lugares de vida.

Nossas descrições sobre os lugares e as paisagens de estudos, poderiam partir das representações espaciais traçadas pelos mapas mentais dos sujeitos que vivem esses lugares, talvez assim, não correríamos o risco de não representar a "flor", que quem sabe pode dizer para que lado corre o vento, de que lado está o sol, que tipo de solo, ela é do lugar? Como os habitantes do lugar interagem com ela: é alimento, remédio, utilizada como oferenda, decora a casa, os lugares de manifestações religiosas, representam o amor ou a morte? Precisamos pensar em uma aproximação com uma geografia da existência, e assim, propor com esse diálogo um mundo que respeite as diversidades sociais, culturais e ambientais da Terra.

\section{REFERÊNCIAS}

BERQUE, Augustin, Paisagem -marca, paisagem-matriz: elementos da problemática para uma Geografia Cultural. In: CORREAA, Roberto Lobato e ROSENDAHL, Zeny (organizadores). Geografia Cultural: uma antologia. V, I. Rio de Janeiro: EdUERJ, 2012.

BUTTIMER, Anne. Apreendendo o dinamismo do mundo vivido. Transcrito dos Anais of the Association of American of Geographes, 66 (2). Junho de 1976. Tradução: Neide Piran e Antônio Chistofoletti. In: CHISTOFOLETTI, Antônio (org.) Perspectiva da Geografia. São Paulo. DIFEL, 1985.

CLAVAL, Paul, A Geografia Cultural. Tradução: Luiz Fugazolla Pimenta e Margareth de Castro Afeche Pimenta. Florianópolis. UFSC,2014.

CLAVAL, Paul, Terra dos Homens: a Geografia. Tradução: Domitila Madureira. São Paulo. Contexto, 2010.

COSGROVE, Denis, A Geografia está em toda parte: cultura e simbolismo nas paisagens Humanas In: CORRÊA, Roberto Lobato e ROSENDAHL, Zeny (organizadores). Geografia Cultural: uma antologia. V.I. Rio de Janeiro. EdUERJ, 2012.

DARDEL, Eric, O Homem e a Terra: natureza da realidade Geográfica.Tradução Werther Holzer.São Paulo. Perspectiva, 2011. 
GANDY, Mathew, Paisagem, estética e ideologias. In: CORRÊA, Roberto Lobato e ROSENDAHL, Zeny (organizadores). Rio de Janeiro. EdUERJ, 2004.

HUSSERL, E. La philosophie comme Science rigoureuse. Paris, PUF. 1955.

HOLZER, Werther, A Geografia Humanista sua trajetória 1950-1990. Londrina, Eduel, 2016.

MERLEAU-PONTY, Maurice, Fenomenologia da percepção. São Paulo, Martins Fontes. 1996.

NOGUEIRA, Amélia Regina Batista. Percepção e representação gráfica: “a geograficidade" nos mapas mentais dos comandantes de embarcações no Amazonas. Manaus, Editora EDUA. 2014.

NOGUEIRA, Amélia Regina Batista, O ensino de Geografia e os desafios para uma abordagem cultural e Humanista. In: PORTUGAL, Jussara Fraga, OLIVEIRA, Simone Santos, RIBEIRO, Solange Lucas (organizadoras), Salvador, EDUFBA. 2016.

SAINT-EXUPÉRY, Antoine, O pequeno Príncipe. Editora Agir, Rio de Janeiro. 2000.

TUAN, Yi-Fu, Topofilia: um estudo da perspectiva da percepção, atitudes e valores do meio ambiente. Tradução Lívia de Oliveira. Londrina, Eduel. 2012.

TUAN, Yi-Fu, Paisagens do Medo. Tradução: Lívia de Oliveira. São Paulo. Editora UNESP, 2005.

TUAN, Yi-Fu, Escapismo: Formas de evasión em el mundo actual. Barcelona. Ediciones Península. 1998. 